\title{
MULTIPLE CHEST LEAD CARDIOGRAMS AND THEIR CLINICAL VALUE*
}

\author{
BY \\ E. H. ROCHE \\ From the Electrocardiographic Department, Auckland Public Hospital, New Zealand \\ Received May 2, 1945
}

The following is a brief contribution to the study of multiple chest lead cardiograms and an assessment of their diagnostic value in a series of 302 cases.

The cardiogram obtained by placing an electrode on the surface of the heart and pairing it with an electrode placed upon a distant part of the body was studied in experimental animals by Lewis and Rothschild in 1915. This pioneer work laid the foundation of modern chest lead cardiograms. The essential parts of Lewis and Rothschild's work were confirmed by numerous animal experiments and by a unique clinical test performed on an exposed human heart by Barker, McLeod, Alexander, and Wilson in 1929. Subsequent investigations have been made by Wolferth and Wood, 1932; Wilson, Hill, and Johnston, 1934; Johnston, Hill, and Wilson, 1935; Kossmann and Johnston, 1935; Wilson, Johnston, and Hill, 1935; Wood and Selzer, 1939; Evans, [1939; and Wilson 'et al., 1944; these have gone far to elucidate the præcordial cardiogram in normal and abnormal hearts and to show that the tracings obtained from the præcordium are essentially the same as those obtained direct from the underlying pericardial surface.

In putting together the following notes, wherein an attempt is made to explain the initial deflections of the præcordial electrocardiogram, the experimental work of these investigators has been freely drawn upon. The form of any cardiogram depends primarily upon the fact that, although the muscle fibres in the heart follow an oblique or circuitous course, the frequent branching and inter-communication between them enables the wave of excitation to pass fairly directly from the endocardial to the pericardial surface. In fact, having quickly traversed the Purkinje system, the excitatory process appears to spread almost centrifugally outwards from the ventricular cavities. We may, therefore, visualize during the QRS interval a wave of positive potential followed closely by a wave of negative potential spreading outwards from each ventricular cavity. These positive and negative charges are held apart by an electromotive force similar to that between the poles of a battery. The contracting muscle over which the wave has passed and the quiescent muscle ahead of the wave behave as normal electrical conductors. Thus the negative potential generated at the proximal side of the wave is conducted backwards to the ventricular cavities and the positive potential generated at the distal side of the wave is conducted outwards to the pericardial surface of the ventricles, but they are not able to neutralize each other by passing in the reverse direction across the wave of excitation. On the contrary, the difference of potential appears to increase as the wave travels so that, within limits, the thicker the ventricular wall, the greater will be the potential difference between its endocardial and pericardial surfaces. Also, where the heart is nearest to the chest wall, its potential will reach an overlying præcordial electrode with the smallest amount of loss in transmission.

From the foregoing principles it follows that the ventricular cavity remains negative so long as the wave of excitation is spreading through any part of the heart muscle, i.e. throughout the QRS interval, after which it returns quickly to zero potential. It is also clear that the pericardial surface is positive for at least part, and nearly always the first part, of the QRS interval. At any point on the pericardial surface; however, the potential switches suddenly to that of the ventricular cavity as soon as that point is reached by the wave of excitation, the

* Read before a Meeting of the Royal Australasian College of Physicians at Christchurch, New Zealand, on February 16, 1945. 
underlying muscle then behaving as a normal electrical conductor. The negative potential of the ventricular cavities is conducted backwards, upwards, and to the right through the auricles and great vessels and is transmitted chiefly to the right upper quadrant of the body which consequently remains negative throughout the QRS interval. Some of the negative charge is, however, conducted forwards from the right auricle and tends to neutralize the positive potential of the adjacent right ventricular pericardium. The positive potential of the pericardial surface of the ventricular muscle on the other hand is chiefly conducted forwards and downwards and to the left, and so dominates the electrical field in the front, left lower, and (usually to a lesser extent) the left upper quadrants of the body.

The initial ventricular deflections of the normal præcordial cardiogram consist of an upstroke (ascending limb of $R$ ) followed by a deep rapid downstroke (intrinsic deflection of Lewis, descending limb of $R$ and $S$ ) and then a return to the iso-electric line. The upstroke is made by the rise of positive potential at the pericardial surface underlying the electrode as the wave of excitation approaches. The intrinsic deflection is made by the rapid switching of the potential at the pericardial surface to that of the ventricular cavity and signalizes the arrival of the wave of excitation at the point on the pericardial surface underlying the electrode, and the return to the iso-electric line is made by the disappearance of the negative potential of the ventricular cavities which may be rapid or relatively gradual according to whether the excitatory process is still spreading through other parts of the heart. Generally speaking, as the examining electrode is moved from right to left across the præcordium it draws closer to the heart muscle which at the same time becomes thicker. When it has passed the septum it begins to move further away from the bifurcation of the bundle and when it has passed the apex it begins to move further away from the surface of the heart. Hence, with a certain reservation that will be mentioned later, the $R$ wave in the cardiogram becomes progressively higher as the electrode moves from the right border to the apex, after which it becomes lower, and it occurs progressively later as the electrode moves from the septum to the axilla.

Frequently the onset of the excitatory process in the septum and adjacent parts of the ventricular wall causes the ventricular cavity to become slightly negative before the impulse has finished spreading through the most distant parts of the Purkinje network. In this event, when a tracing is taken from the left side of the præcordium the negative potential is conducted electrically from the cavity through the as yet quiescent muscle underlying the electrode and causes a negative deflection (descending limb of the $Q$ wave) in the cardiogram. The $R$ wave then occurs relatively late in the QRS interval and the arrival of the wave of excitation at the pericardial surface underlying the electrode will mark the end or very nearly the end of the excitatory process in the heart. It will therefore mark the end or very nearly the end of the negative potential in the ventricular cavities. Thus the intrinsic deflection in the cardiogram will terminate at or very near the base line and there will be little or no $S$ wave. The behaviour of the $\mathrm{T}$ wave is still in some cases obscure. Although it is well known that during the $T$ wave the myocardium is relaxing, the nature of this process and its variations from normal are not so clearly understood. Its interpretation, therefore, remains to some extent empirical.

Characteristic variations from the normal QRS complexes are produced by certain forms of ventricular hypertrophy or damage. In the case of left ventricular preponderance the normal differences between the two sides of the præcordium are increased. On the right side of the præcordium the positive potential is apparently neutralized by the increased negative potential generated in the left ventricle and conducted from the cavity of that ventricle through the auricles and adjacent tissues. Consequently the $R$ wave is very small or absent and the $\mathrm{S}$ wave is deeper and somewhat wider than usual. Complexes of this type extend well across the præcordium and may be obtained from the apex. Still further to the left the $\mathbf{R}$ wave suddenly becomes abnormally high and rather wide and tends to occur rather late, and is therefore frequently preceded by a $Q$ wave. The transition from the small to the high $R$ wave observed in the 3rd, 4th, or 5th chest lead is marked by inversion of the $T$ wave.

In right ventricular preponderance the $R$ wave is highest on the right side of the præcordium usually in the 2nd or 3rd chest lead, where $\mathrm{T}$ is frequently inverted and $\mathrm{Q}$ may be present, $\mathrm{S}$ is small or absent. In this condition leads from the left side show a small $\mathrm{R}$ similar to that normally found on the right side and $\mathrm{S}$ is correspondingly deep; $\mathrm{T}$ is upright. 
In bundle branch block the septum on the affected side distal to the block remains quiescent until the excitatory process from the unaffected side has spread through the septum. While the septum is the seat of a spreading excitatory process, positive potential is generated upon its quiescent surface. This is conducted through the cavity and free wall of the ventricle and rèsults in a small $R$ wave on the affected side of the præcordium. The completion of the excitatory process in the septum causes the potential of the affected side to switch to that of the opposite ventricular cavity. This negative potential causes an $S$ wave or a notch upon the $\mathrm{R}$ wave in tracings from the præcordium on the affected side. The subsequent spread of the excitatory process in the free wall of the affected ventricle causes a second rise of positive potential which reaches the chest wall far out on the affected side. There will thus be a secondary $\mathrm{R}$ wave which may be followed by a more or less normal intrinsic deflection or the return to the base line may be rather slurred. In the case of left bundle branch block the secondary $\mathrm{R}$ wave is frequently obtained only from the axillary leads. Tracings from the præcordium overlying the normal bundle differ from the normal cardiogram only in that the $\mathrm{R}$ wave is small or absent and the return of the $\mathrm{S}$ wave to the iso-electric line is delayed. The widening of $\mathrm{S}$ is due to the late excitatory process in the opposite ventricle, the negative potential generated therein being conducted across the septum and through the cavity and contracting free wall of the normal ventricle, and so to the præcordium.

In myocardial infarction the damaged muscle conducts electricity in a normal manner, but cannot respond to the wave of excitation. If the infarct involves the whole thickness of the ventricular wall, the potential of its pericardial surface must at all times be that of the ventricular cavity. It is therefore negative throughout the $\mathrm{QRS}$ interval and there is no $\mathrm{R}$ wave in the cardiogram from that region. The $T$ wave is inverted over the infarct and over a region surrounding the infarct where the myocardial changes are of minor degree. If the infarct involves the endocardial surface, but not the whole thickness of the ventricular wall, the negative potential of the ventricular cavity is at first conducted through infarct and normal muscle to the surface of the chest, and the first part of the QRS complex consists of a $\mathrm{Q}$ wave. Then, as the wave of excitation, spreading outwards around the periphery of the infarct, reaches and spreads through the normal muscle between the infarct and the pericardial suthe an upstroke will be registered which may or may not go above the base line. On the arrival of the excitatory process at the pericardial surface overlying the infarct there is a return to zero potential unless the excitatory process is still spreading through other parts of the heart, in which case there will be a secondary negative wave.

From these considerations it will be apparent that the QRS complexes of the præcordial cardiograms, unlike those of the standard leads whose interpretation is still largely empirical, lend themselves to rational interpretation and that most of the common findings can be explained in terms of myocardial pathology.

\section{RESUlts OBTAINED}

Before proceeding to analyse a series of cardiograms, certain points of technique call for consideration. If, as in the series under review, the præcordial electrode is paired with the left lower limb, the tracing will be modified by the potential variations of the limb, and as this is almost always positive during the QRS interval and during the T wave, the result will be a shift towards negative voltage in the cardiogram; and a fictitious absence of the $R$ wave or inversion of the $\mathrm{T}$ wave will sometimes occur. The error from this source is equal to one third of the algebraic sum of standard leads II and III. The necessary correction would be relatively simple if it applied to the summits of the waves. Unfortunately it applies only to the height of the wave at a given moment of time and as the summits of the three leads concerned are not in phase and usually do not coincide, the correction is too complicated for routine practice. In all cases in the present series where an abnormality was present or suspected, the above correction was, however, applied before interpretation of the findings: A better method is to pair the præcordial electrode with a neutral area (Wolferth and Livezey, 1944), or, as we now prefer, a central terminal such as Goldberger's modification of the Wilson assembly (Goldberger, 1942).

Brief mention must also be made of the points chosen for the præcordial electrode. In 
their supplementary report (1938) the committee of the American Heart Association recommended a number of standard positions related to the surface markings of the chest wall irrespective of the size and position of the heart. Thus the committee recommended that the fourth position be at the intersection of the left mid-clavicular line and the fifth space, and that the third position be midway between this point and the left border of the sternum in the fourth space. As, however, the aim of this investigation was to study the electrical field overlying particular areas of the heart's surface, it was thought desirable that the points selected on the chest wall should bear as constant a relationship as possible to the anatomy of the heart. It has, therefore, been the practice in all the cardiograms now under review to take the fourth chest lead from the outer border of the cardiac apex instead of from the midclavicular line whose relation to the heart is variable, and to take the third chest lead from a point?midway between the apex and the left sternal border in the fourth space. In cases where the impulse cannot be clearly felt the apex is assumed to be in the mid-clavicular line.

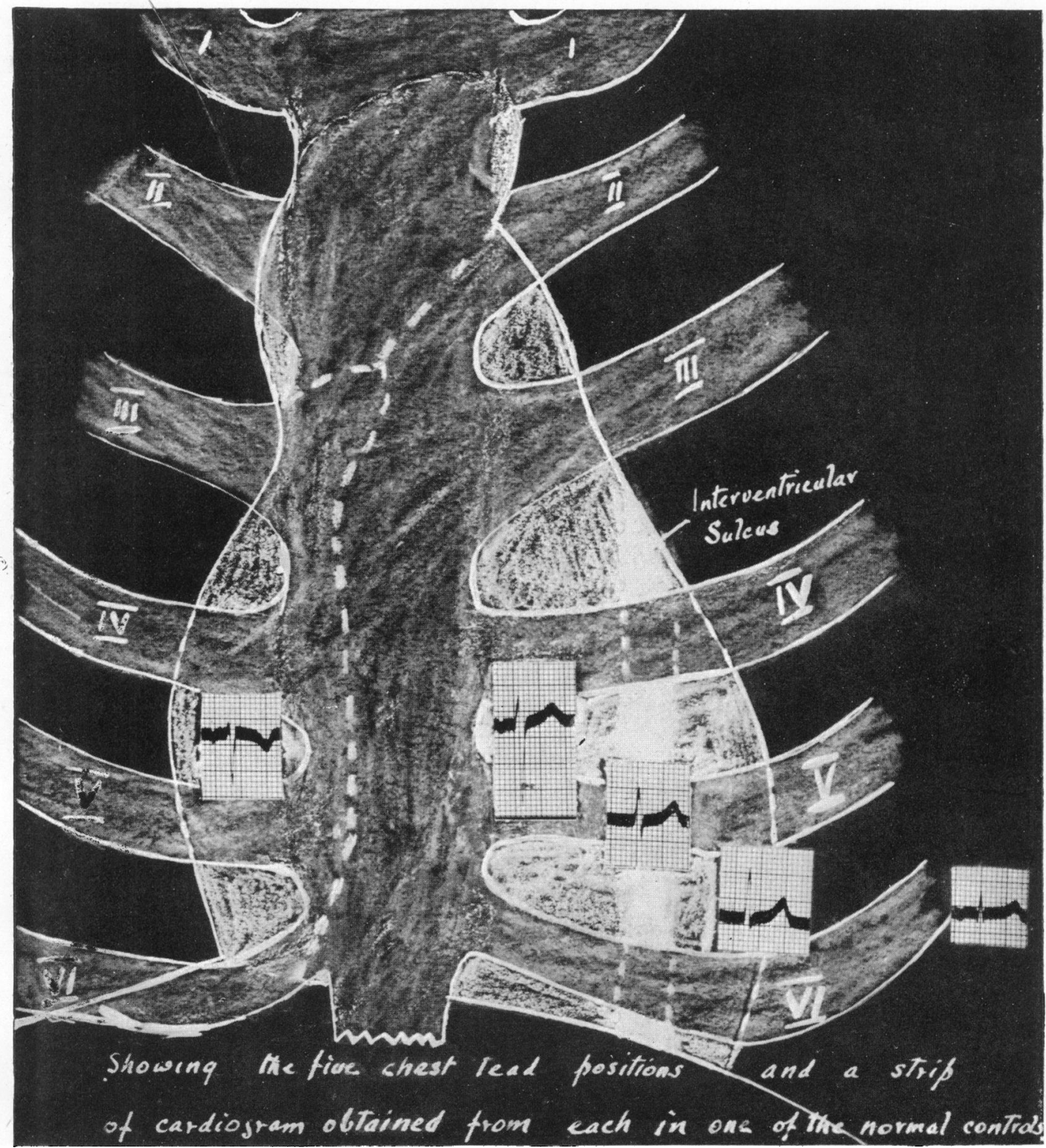

FIG. 1. 
This method has also the advantage that the fourth chest lead is identical with lead IV, provided it has been paired with the same indifferent electrode. This is of some importance when a comparison is being made with other cardiograms where only one præcordial lead has been taken. In all other respects the recommendations of the committee of the American Heart Association have been followed. The five points are indicated in the figure by portions of the cardiogram obtained therefrom in a normal subject.

The following is a study of 302 cases in which five chest lead cardiograms CF 1, 2, 3, 4, and 5 were taken and in which full clinical histories were available. They include 218 cases from private practice, being all the cases in which a cardiogram was considered necessary between certain dates, 78 hospital cases, and 6 normal controls. The hospital group comprises all the cases in which a cardiogram was taken during a limited period when all cardiograms were taken with multiple chest leads. With the exception of the 6 controls they all had real or suspected heart disease, but otherwise they were in no way selected. In a short series the average time required for the taking of the five chest leads after the completion of the standard leads was four minutes. All the cardiograms were re-examined and classified under nine headings according to the diagnostic information gleaned from the standard leads on the one hand and the chest leads on the other. In making the classification the standard lead cardiogram was considered doubtful when the QRS complexes were of low voltage (total deflections of the three leads less than $15 \mathrm{~mm}$.), or when the R S-T take off was depressed $1 \mathrm{~mm}$. in leads I or II, or the T wave in these leads measured only $0.5 \mathrm{~mm}$. Ventricular preponderance was considered abnormal, but axis deviation without $\mathrm{T}$ wave inversion or significant R S-T displacement was ignored. The chest lead cardiogram was considered doubtful when the maximum $T$ wave was between 1 and $2 \mathrm{~mm}$. or where splintering.without widening occurred in one of the $\mathrm{S}$ waves from the right side of the heart or where there was a dip of $1 \mathrm{~mm}$. in the $\mathrm{R}$ or $\mathrm{T}$ gradients.

TABLE I

A Comparison of the Frequency with Which Abnormalities were revealed by Standard and Chest LEADS IN A SERIES OF 302 CASES

\begin{tabular}{c|c|c|c|c|c|c|c|c|c}
\hline $\begin{array}{c}\text { Standard } \\
\text { Leads }\end{array}$ & Normal & Normal & Normal & Doubtful & Doubtful & Doubtful & Abnormal & Abnormal & Abnormal \\
$\begin{array}{c}\text { Chest } \\
\text { leads }\end{array}$ & Normal & Abnormal & Doubtful & Abnormal & Doubtful & Normal & Normal & Doubtful & Abnormal \\
\hline $\begin{array}{c}\text { Number } \\
\text { of cases }\end{array}$ & 122 & 40 & 19 & 29 & 8 & 6 & 3 & 2 & 65 \\
$\begin{array}{c}\text { Percentage } \\
\text { of cases }\end{array}$ & 41 & 13.5 & 6.5 & 10 & 3 & 2 & 1 & 1 & 22 \\
\hline
\end{tabular}

Table I shows that the standard leads were normal in 181 cases and of these the chest leads were abnormal in 40 and doubtful in 19; the standard leads were doubtful in 43 cases and of these the chest leads were abnormal in 29, doubtful in 9 and normal in 6; the standard leads were abnormal in 70 cases and of these the chest leads were normal in only 3 and doubtful in 2. Both were normal in 122 cases and abnormal in 65 cases; of these 65 cases the chest leads were considered to yield extra information in 27. These were cases in which an arrhythmia or prolonged P-R interval or ventricular preponderance was the only abnormality present in the standard leads and where the chest leads revealed QRS splintering or a major fault in the $\mathrm{R}$ or $\mathrm{T}$ wave gradient, amounting in many cases to evidence of infarction. An analysis of the clinical histories of the 69 cases in which the cardiogram was normal in the standard leads and abnormal or doubtful in the chest leads may be set out as follows.

\section{Certain cardiac pathology}

Strong history of myocardial infarction with or without angina of effort Congestive heart failure

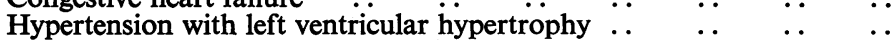

Congenital pulmonary stenosis with septal defect $\quad \cdots \quad \ldots$

Previous history of failure with complete heart block lasting 5 days ..

Asthma with right ventricular hypertrophy TOTAL with definite cardiac pathology

$\begin{array}{llll}\cdots & \ldots & \ldots & \ldots\end{array}$

$$
\begin{array}{llr}
\ldots & \ldots & 32 \\
\ldots & \ldots & 3 \\
\ldots & \ldots & 1 \\
\ldots & \ldots & 1 \\
\ldots & \ldots & 1 \\
. . & \ldots & 1 \\
& & 39(56 \text { per cent })
\end{array}
$$

$\mathbf{L}$ 
Probable cardiac pathology

$\begin{array}{llllllllll}\text { Angina of effort with no clear history of infarction } & \ldots & \ldots & \ldots & \ldots & \ldots & 8\end{array}$

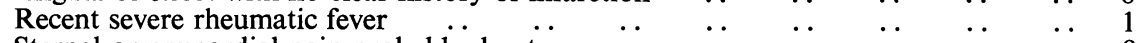

Sternal or præcordial pain probably due to coronary spasm $\quad \ldots \quad$.

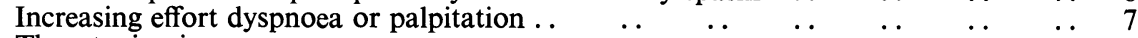

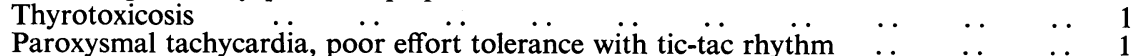

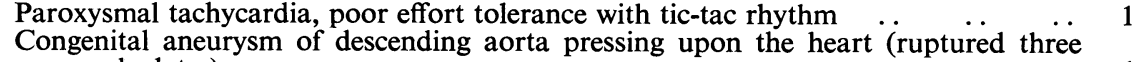

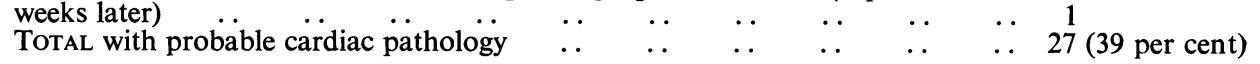

Possible cardiac pathology

$\begin{array}{llllllllll}\text { Sternal or præcordial pain probably not cardiac . } & \ldots & \ldots & \ldots & \ldots & \ldots & 3 \\ \text { Asthma (heart not screened) } & \ldots & \ldots & \ldots & \ldots & \ldots & \ldots & \ldots & 1\end{array}$

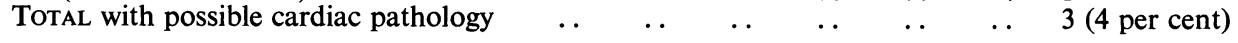

There were only five cases in which the cardiogram was normal or doubtful in the chest leads and abnormal in the standard leads. The following is an analysis of these.

\section{Certain cardiac pathology}

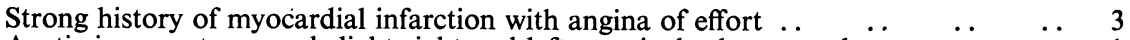

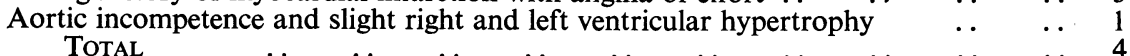

Probable cardiac pathology

$\mathbf{P}-\mathbf{R}$ interval $\mathbf{0} \cdot 21 \mathrm{sec}$. (normal $\mathbf{P}-\mathbf{R}$ interval chest leads)

All the cases of myocardial infarction were of the T III (posterior) type.

The above figures show conclusively that where the standard leads are normal or doubtful and the chest leads are abnormal, the clinical findings (except in cases of posterior infarction) strongly support the chest leads. It was noted that the lead from the apex indicated myocardial damage rather more frequently than any other single lead. At the same time, out of 40 cases in which the chest leads provided the sole cardiographic evidence of disease, that evidence was solely present in leads other than the apical in 21 . In all but two of these the diagnosis of myocardial damage was supported by strong or fairly strong clinical evidence.

Measurements of the amplitudes of the $\mathrm{R}$ and $\mathrm{T}$ waves of all the chest leads were made in 192 consecutive cases and in 40 other selected cases. The selected group comprised all the remaining cases with abnormal chest leads (34) and 6 normal controls, three of the latter being tall and slender and three short and broad. If the amplitudes of the $\mathrm{R}$ waves in the five chest leads are plotted graphically in order from the 1st to the 5th chest lead, a curve is obtained that represents the distribution of positive potential across the præcordium during the spread of the excitatory process through the heart: for convenience we shall call it the $\mathrm{R}$ gradient. Similarly, if the amplitudes of the $\mathrm{T}$ waves are plotted in the same order, a curve will be obtained which may be termed the T gradient. Kossman and Johnston (1935), from a study of 30 normal students, observed that "the average voltage of the $\mathrm{R}$ deflection increased progressively in the first four præcordial leads and was nearly as great in the fifth as in the fourth." They also noted that " the average voltage of the $T$ wave was greatest in the 2 nd and 3rd præcordial leads and showed a progressive decrease in leads taken further to the left." These observations prompted the following study of the $\mathrm{R}$ and $\mathrm{T}$ gradients.

In slightly more than half ( 58 per cent of our series) the form of the $\mathrm{R}$ gradient supported Kossman and Johnston's findings. But in a considerable number some portion of the gradient was flat or even presented a dip. An analysis showed that the gradient was flat from the second to the third lead in 23 cases (10 per cent of the series), from the first to the second lead in 16 cases ( 17 per cent), from the first to the third in 6 cases ( 3 per cent), from the first to the fourth in 7 cases ( 3 per cent), and from the second to the fourth in 6 cases ( 3 per cent). In all cases in which the gradient was flat from the first to the fourth leads the amplitude of the $\mathrm{R}$ wave was zero, and of the 6 in which the gradient was flat from the second to the fourth chest leads the amplitude was zero in 3 and $1 \mathrm{~mm}$. in 3 cases. In both these groups there was clinical or cardiographic evidence of myocardial damage (apart from the $\mathrm{R}$ waves) in all the cases. In 27 cases (12 per cent), a rising or horizontal $\mathrm{R}$ gradient was observed to dip slightly and to rise again as the electrode moved further to the left. In 17 cases ( 7 per cent) 
a similar dip was observed in the $\mathrm{T}$ gradient and in 6 of these a dip occurred in both gradients together. It should be emphasized that a dip in the $\mathrm{T}$ gradient does not necessarily imply inversion. All the cases presenting a plateau or a dip in the gradient were classified under four heads according to whether on clinical or other evidence it was considered that myocardial damage was certain, probable, possible, or absent.

The results are set out in Table II showing the number of cases in each group and the percentage of the various grades of myocardial damage in each group and for the whole series. It will be observed that myocardial disease was present in 46 per cent, and probably in another 14 per cent, these two groups together comprising 60 per cent of the whole series. In the group with a flat gradient from 1 to 2 there were 63 per cent with definite pathology, and 6 per cent with probable pathology, making a total of 69 per cent with definite or probable pathology. In the group with a flat gradient from 2 to 3 the figures were 57 per cent and 17 per cent, making a total of 74 per cent with definite or probable myocardial pathology. In the group with a flat gradient from 1 to 3 the figures were 67 per cent and 16 per cent, making a a total of 83 per cent. In the groups with a flat gradient from the 1st to the 4th, or from the 2nd to the 4th, there was, as previously stated, clear myocardial pathology in all cases.

\section{TABLE II}

The Association between Myocardial Damage and some features of the $R$ and $T$ Gradients

\begin{tabular}{|c|c|c|c|c|c|c|c|c|c|c|c|}
\hline \multirow{2}{*}{$\begin{array}{l}\text { Leads } \\
\text { involved }\end{array}$} & \multicolumn{5}{|c|}{ Flat portion of $\mathbf{R}$ gradient } & \multicolumn{2}{|c|}{$\begin{array}{l}\text { Dip in } \\
\mathbf{R} \text { gradient }\end{array}$} & \multicolumn{2}{|c|}{$\begin{array}{l}\text { Dip in } \\
T \text { gradient }\end{array}$} & \multirow{2}{*}{\begin{tabular}{|} 
Dip \\
common \\
to both \\
gradients
\end{tabular}} & \multirow{2}{*}{$\begin{array}{l}\text { Whole } \\
\text { Series }\end{array}$} \\
\hline & $1 \& 2$ & $2 \& 3$ & $1,2,3$ & $|1,2,3,4|$ & $2,3,4$ & $\begin{array}{c}\text { Greater } \\
\text { than } \\
1 \mathrm{~mm} .\end{array}$ & $\begin{array}{c}1 \mathrm{~mm} . \\
\text { or } \\
\text { less }\end{array}$ & $\begin{array}{c}\text { Greater } \\
\text { than } \\
1 \mathrm{~mm} .\end{array}$ & $\begin{array}{c}1 \mathrm{~mm} . \\
\text { or } \\
\text { less }\end{array}$ & & \\
\hline No. of cases & 16 & 23 & 6 & 7 & 6 & 10 & 17 & 12 & 5 & 6 & 232 \\
\hline 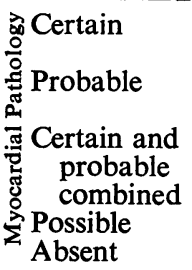 & $\begin{array}{c}10 \\
63 \% \\
1 \\
6 \% \\
69 \% \\
3 \\
2\end{array}$ & $\begin{array}{l}13 \\
57 \% \\
4 \\
17 \% \\
74 \% \\
\\
5 \\
1\end{array}$ & $\begin{array}{c}4 \\
67 \% \\
1 \\
16 \% \\
83 \% \\
1 \\
-\end{array}$ & $\begin{array}{l}7 \\
100 \% \\
- \\
- \\
100 \% \\
- \\
-\end{array}$ & $\begin{array}{l}6 \\
100 \% \\
- \\
100 \% \\
- \\
-\end{array}$ & $\begin{array}{c}6 \\
60 \% \\
1 \\
10 \% \\
70 \% \\
3 \\
-\end{array}$ & $\begin{array}{l}10 \\
59 \% \\
3 \\
18 \% \\
76 \% \\
\\
3 \\
1\end{array}$ & $\begin{array}{c}8 \\
67 \% \\
2 \\
17 \% \\
83 \% \\
2 \\
-\end{array}$ & $\begin{array}{l}1 \\
20 \% \\
- \\
20 \% \\
1 \\
3\end{array}$ & $\begin{array}{c}3 \\
50 \% \\
- \\
- \\
50 \% \\
2 \\
1\end{array}$ & $\begin{array}{c}106 \\
46 \% \\
33 \\
14 \% \\
60 \% \\
55 \\
58\end{array}$ \\
\hline
\end{tabular}

There would thus appear to be a real correlation between a plateau upon the $\mathrm{R}$ gradient and the presence of myocardial damage specially when the plateau involves the $2 \mathrm{nd}$, 3rd, and 4th chest leads. It was noted, however, that such a plateau was in many cases associated with low $\mathrm{R}$ wave voltages which are in themselves of some diagnostic import.

It will also be seen from Table II that the incidence of certain myocardial pathology is somewhat higher than the average for the series in those cases showing a dip in the R gradient, whether greater or less than $1 \mathrm{~mm}$. and in those cases showing a dip of more than $1 \mathrm{~mm}$. in the $\mathrm{T}$ gradient. The incidence of probable myocardial pathology in these groups as a whole, however, is not significantly above the average for the whole series. It is also apparent that in cases where the dip in the $\mathrm{T}$ wave is $1 \mathrm{~mm}$. or less, or where a dip occurs in both gradients simultaneously, the incidence of certain and probable myocardial pathology taken together is below the average.' Furthermore, one of the 6 normal cases presented a small dip in both $\mathrm{R}$ and $\mathrm{T}$ gradients. It was observed that a majority of the dips in the gradients occurred in the third chest lead, which in this series of cases was taken, as previously mentioned, from the region overlying the septum and interventricular sulcus. In this sulcus lies the coronary artery embedded sometimes in a considerable thickness of fat, which, as Kaufman and Johnston, 1943, have pointed out, is a very poor electrical conductor. Thus, not only does the heart muscle in this situation dip slightly away from the chest wall, but there is also interposed the high resistance of a layer of fat. It would seem that this would be sufficient to 
account for a dip in both $\mathrm{R}$ and $\mathrm{T}$ gradients. It would not, however, explain a dip occurring in the second or fourth lead.

In Table III, therefore, the gradients are grouped according to whether the dip occurs in the third lead alone, or whether the second or fourth chest lead is involved either alone or in addition to the third, and the correlation of the two groups with the presence of myocardial damage is shown. It will be seen that when the third lead alone is involved, the incidence of certain and probable myocardial damage is only slightly higher than the average for the whole series. When the second lead is involved, the incidence of certain myocardial damage is 75 per cent, and when the fourth lead is involved, the incidence of certain myocardial damage is 100 per cent in the case of the $\mathrm{R}$ gradient and 86 per cent in the case of the $T$ gradient. In the remaining case showing a dip in the $T$ gradient in the fourth lead myocardial damage was considered clinically probable. It was also observed that when there was an $\mathrm{R}$ wave, however small, in the first lead and no $R$ or $R^{1}$ in the second lead, myocardial pathology was present in every case. It would appear, therefore, that while a dip in either or both gradients in the third lead alone is of little or no significance, a dip of any degree involving the second or fourth lead is strongly indicative of myocardial damage. In clinical practice all the features of the $\mathrm{R}$ and $\mathrm{T}$ gradients can readily be appreciated by the eye without any graphical plotting and actual measurements are seldom required.

TABLE III

The Association between Myocardial Damage and the Position of the Dip in the R and T Gradients

\begin{tabular}{|c|c|c|c|c|c|c|}
\hline \multirow{2}{*}{ Myocardial Pathology } & \multicolumn{3}{|c|}{ Dip in $\mathbf{R}$ gradient } & \multicolumn{2}{|c|}{ Dip in $\mathrm{T}$ Gradient } & \multirow{2}{*}{$\begin{array}{c}\text { Whole } \\
\text { series }\end{array}$} \\
\hline & $\begin{array}{l}\text { In } 3 \text { rd lead } \\
\text { only }\end{array}$ & $\begin{array}{l}\text { Involving } \\
\text { 2nd lead }\end{array}$ & $\begin{array}{l}\text { Involving } \\
4 \text { th lead }\end{array}$ & $\begin{array}{l}\text { In } 3 \text { rd lead } \\
\text { only }\end{array}$ & $\begin{array}{l}\text { Involving } \\
\text { 4th lead }\end{array}$ & \\
\hline $\begin{array}{l}\text { Certain } \\
\text { Probable } \\
\text { Possible. } \\
\text { Absent }\end{array}$ & $\begin{array}{c}10(47 \%) \\
4(19 \%) \\
6(29 \%) \\
1(5 \%)\end{array}$ & $\begin{array}{c}3(75 \%) \\
1(25 \%) \\
=\end{array}$ & $\begin{array}{c}6(100 \%) \\
- \\
-\end{array}$ & $\begin{array}{l}3(30 \%) \\
1(10 \%) \\
3(30 \%) \\
3(30 \%)\end{array}$ & $\begin{array}{c}6(86 \%) \\
1(14 \%) \\
-\end{array}$ & $\begin{array}{l}(46 \%) \\
(14 \%) \\
(24 \%) \\
(16 \%)\end{array}$ \\
\hline
\end{tabular}

One further comment should be made on the third chest lead. Two cases of marked QRS splintering in this lead were associated with very doubtful clinical histories of myocardial damage. As the examining electrode in this lead is astride both ventricles it is conceivable that some anatomical asymmetry in the arrangement of the conducting mechanism on the two sides may account for such splintering in rare cases. It may not, therefore, necessarily indicate any pathology and pending further investigation it is suggested that this finding be interpreted with caution.

\section{CONCLUSIONS}

The principles underlying the interpretation of chest leads are discussed.

The normal $\mathrm{R}$ and $\mathrm{T}$ gradients obtained from multiple chest leads are described.

An analysis is made of a series of 302 cases in which multiple chest leads CF 1, 2, 3, 4, and 5 were taken, and from this the observations that follow were made.

The chest leads provided the sole electrocardiographic evidence of myocardial damage in 40 cases (13 per cent) and of these the evidence was solely present in leads other than the apical in 21 .

When the fourth lead was involved in a plateau or a dip of the $\mathrm{R}$ gradient, myocardial damage was present in every case; and when the second lead was involved in a dip of the $R$ gradient or the fourth lead in a dip of the $\mathrm{T}$ gradient damage was present in a high proportion of cases.

A dip of the $\mathrm{R}$ or $\mathrm{T}$ or both gradients in the third lead is a normal finding. 


\section{REFERENCES}

Barker, P. S., MacLeod, A., Alexander, J., and Wilson, F. N. (1929). Trans. Assoc. Amer. Phys., 44, 125.

Committee of the American Heart Association for the Standardization of Præcordial Leads (1938. Amer. Heart J., 15, 235.

Evans, C. (1939). Brit. Heart J., 1, 161.

Goldberger, E. (1942). Amer. Heart J., 23, 483.

Johnston, F. D., Hill, I. G. W., and Wilson, F. N. (1935). Ibid., J., 10, 889.

Kossman, C. E., and Johnston, F. D. (1935). Ibid., 10, 925.

Lewis, T., and Rothschild, M. A. (1915). Phil. Trans. Roy. Soc. Lond., Series B, 206, 181.

Wilson, F. N., Hill, I. G. W., and Johnston, F. D. (1934). Amer. Heart J., 10, 163.

Wilson, F. N., Johnston, F. D., and Hill, I. G. W. (1935). Ibid., 10, 1025.

Wilson, F. N., Johnston, F. D., Rosenbaum, F. F., Erlanger H., Kossman C. E., Hecht H., Cottrim, N., de Oliveire R. M., Scarsi R., and Barker P. S., Ibid., (1944), 27, 19.

Wolferth, C. C. and Wood, F. C. (1932). Amer. J. med. Sci., 183, 30.

Wolferth C. C., and Livezey, M. M. (1944). Amer. Heart J., 27, 764.

Wood, P., and Selzer, A. (1939). Brit. Heart J., 1, 49. 